\title{
A HISTORY OF CENTRAL COLLISIONS AT THE BEVALAC
}

\author{
Arthur M. Poskanzer \\ Nuclear Science Division \\ Laurence Berkeley Laboralory \\ 1 Cyclotron Road \\ Berkcley, CA 94720
}

July 13, 1989

Invited talk presented at the NATO advanced study institute on

The Nuclear Equation of State

Periscola, Spain

21 May-3 June, 1989

\section{DLSClaIMER}

\begin{abstract}
This report was prepared as an account of work sponsored by an egency of the United Statea Covernment. Neither the United States Soverament nor any asency theroof, nor any of their employes, makes any warranty, expres or implied, or asumes any kegal liability or reapomibility for the accuracy, completenea, or usefulness of any information, apparatus, product, or process disclowed, or represents that its use would not infringe privately owned rights. Reference herein to any specific commercial product, proceas, or service by trade name, trademark, manufacturer, of otherwixe does not necessarily constitute or imply its endorsement, recommendation, or favoring by the Uniled State Government of any asency thereof. The views and opinions of authors expresed herein do not necesearily state or reflect those of the United States Government or any agency thereof.
\end{abstract}

This work was supported by the Director, Office of Energy Rescarch, Office of High Energy and Nuclear Physics, Division of Nuclear Physics, of the U.S. Department of Energy under Contract DE-AC03-76SF00098. 


\title{
A HISTORY OF CENTRAL COLLISIONS AT THE BEVALAC
}

\author{
Arthur M. Poskanzer \\ Lawrence Berkelcy Laboratory \\ Berkcley, CA 94720
}

You have heard a great deal about Plastic Ball results at this conference. There were talks on the first morning by Hans-Georg Ritter and Karl-Heinz Kampert on the Plastic Ball at Berkeley, there will be a talk next week by Rudi Schmidt on the Plastic Ball at CERN, and many other speakers have mentioned Plastic Ball results. The young students may think that when the new ficld of relativistic heavy ion physics opened up, an ideal detector was designed and built, data immediately analyzed, and results produced. The theme of my talk is to show that this is incorrect. The experiments proceeded in logical stages, one building upon the other, increasing in complexity and sophistication. The analysis techniques and the theory developeil along with the experiments. If the more senior people in the audience easily remember this history of the development of the relativistic heavy ion ficld, they may spend their time during this talk thinking about what is happening now and what will happen in the future in the ultrarelativistic heavy ion field, where I believe history is repeating itself.

\section{EARLY HISTORY}

My story (which only concerns experiments with which I have been associaled) starts in the late 60 's at the Bevatron, where I was studying high energy proton-nucleus collisions such as $5.5 \mathrm{GeV}$ protons on uranium. With small silicon $\mathrm{dE} / \mathrm{dx}-\mathrm{E}$ telescopes, we were measuring energy spectra at various angles to the beam of what were then called the fragmentation products produced from high deposition energy reactions. These reactions we would now call cintral proton-nucleus collisions. The so-called fragmentation products, helium up through carbon or nitrogen, we would now call intermediate mass fragments. Earl Hyde and I studied these reactions systematically (see Fig. 1), measuring the energy spectra and angular distributions of all the isotopes. 1 There were several anomalies shown which are still not completely understood. These included the apparent low Coulomb barriers, the high "temperatures", and the higher "temperatures" for the neutron deficient isotopes. In addition, the angular distributions were forward peaked in the moving system deduced from the shifts in the energy spectra. In 1974 deuteron and alpha particle beams arrived at $2.1 \mathrm{GeV} /$ nucleon. Although the yields of these 
fragmentation products were higher, the energy spectra displayed apparent temperatures that were only very slightly higher. ${ }^{2}$ The small differences produced by the alpha beams compared to proton beams were disappointing.

\section{THE GSI-LBL COLLABORATION}

In July 1974 Reinhard Stock and Rudolf Bock came to visit me to talk about starting a collaboration. We spent three hours in my office calculating what would be the best experiment to do with the upcoming heavier ion beams. Because of the expected low beam intensities, time of flight techniques with small solid angle were ruled out and we decided on a large area $\mathrm{dE} / \mathrm{d} x-\mathrm{E}$ telescope made ot an array of silicon and germp. : . . . . - thers. The plan was to continue the study of the fragmentation products with the hra GSI-LBL collaboration and in the fall of 1974 "ans $C_{2}, ' r$, and Andres Sandoval arrived.

In 1974 the transfer line was completed connecting the SuperHILAC to the Bevatron, creating the Bevalac which could produce $2 \mathrm{GcV} /$ mucleon heavy ions, an energy more than 100 times higher than previously available. Initially the heaviest beam was oxygen, but the mass increased later to neon. In this new energy regime it was hard to imagine what to expect. Because this field of relativistic heavy io! physics was completely new to all of us, group meetings were very exciting, as everybody contributed on an equal basis. Nobody had any experience and the young peuple, as you will see, participated equally with the more senior people.

\section{SHOCK WAVES?}

While the large area silicon-germanium telescope was being planned and built, Prof. Schopper reported his shock wave peaks in AgCl track detectors irradiated by $0.9 \mathrm{GeV} /$ nucleon oxygen ions. ${ }^{3}$ In his angular distributions he observed a broad peak with small narrower peaks superimposed. We decided to proceed quickly to verify this. We took a $5 \mathrm{~cm}$ thick piece of plastic scintillator, slapped it on a phototube, put a $1 \mathrm{~mm}$ thick $\mathrm{Li}$ drift silicon detector in front of it, and placed it in my existing scattering chamber (sce Fig. 2). This silicon-plastic telescope was designed to look for ${ }^{3} \mathrm{He}$ and ${ }^{4} \mathrm{He}$ fragments. We used a $1 \mathrm{GeV} /$ nucleon oxygen beam to irradiate a silver target in order to approximate the conditions of the silver chloride track detectors. Our results ${ }^{4}$ in 1975 when plotted (see Fig. 3 top) as $\mathrm{d} \sigma / \mathrm{d} \theta$ showed a nice broad peak at about 60 degrees in the laboratory, similar to the data of Prof. Schopper. However, plotting the data (see Fig. 3 bottom) as $\mathrm{d} \sigma / \mathrm{d} \Omega$, the way we thought it should be plotted, produced curves which were exponentially decreasing smooth lines with increasing laboratory angle. No peaks were observed - nothing that we could call a shock wave. It must be remembered that Prof. Schopper's small peaks were obtained by subtracting an evaporation component and using a method of three channel smoothing which is known to make statistical fluctuations appear more significant. In fact the narrow peaks have never been verified in later data which have clearly shown the collective flow effect.

\section{ROUGH UNDERSTANDING}

In 1976 we built a second silicon-plastic telescope which could measure protons as well as helium fragments. It consisled of a $2 \mathrm{~mm}$ thick Li drifted silicon detector and a $10 \mathrm{~cm}$ thick plastic scintillator. The old silicon-plaslic telescope was used as a monitor retector. In addition a thin rounded dome was put on the scattering chamber and 15 plastic scintillators were placed outside the chamber as an associated multiplicity tag array (see Figs. 4 \& 5). We quickly learned that a 
multiplicity array which covers only part of the solid angle is very sensitive to fluctuations in the number of particles which go into the array, so that one could not select on high multiplicity events. However, having for the first time a telescope which could measure protons in addition to the heavier fragments, opened up to us a whole new world of physics. A young theoretician working with us, Jannik Johansen, discovered in 1976 that the spectra of the deuterons, tritons, ${ }^{3} \mathrm{He}$, and ${ }^{4} \mathrm{He}$ particles could be explained in terms of the proton spectra raised to the $\mathrm{A}^{\text {th }}$ power (see Fig. 6). This was the first use of the Coalescence Model in relativistic heavy ion physics ${ }^{5}$, and changed the whole emphasis of the work away from the fragmentation products to the protons. Only a few months later a young post-doc, Gary Westfall, combined the spectator-participant model of Wladek Swiatecki with a thermal breakup of the participant nucleons and found he could qualitatively describe the proton data (see Fig. 7). This was the birth of the Nuclear Fircball Model ${ }^{6}$ (see Fig. 8), and suddenly we were in the exciting position that a rough description of all the data was at hand. Of course this was a tremendous stimulus to the theoreticians to try to do better.

By now the large area silicon-germanium telescope was ready (see Fig, 9), but we were now no longer interested in the intermediate mass fragments! However, we made systematic measurements of these fragments in 1976 and published them together with a summary of all our other work in a big paper in 1977. This paper, called "Central Collisions of Relativistic Heavy lons"7, is strongly recommended for the student. The Bevalac beams had only gotten as heavy as ${ }^{20} \mathrm{Ne}$ at that time, but the paper describes the use of rapidity plots, methods to analyze associated multiplicity, and a complete summary of the Coalescence and Fircball models. Of the authors of that paper, Jean Cosset and Gary Westfall have gone on to build their own $4 \pi$ detectors, Hans Gutbrod, Reinhard Stock, Andres Sandoval and myself are in the CERN program, and Bill Meyer has gone to Bell Labs.

Since the main interest now was no longer the heavier fragments but was concentrated in finding out where the total mass from the reaction was going, we decided to concentrate on the hydrogen and helium isolopes. A new thick silicon-germanium telescope was built in 1977, consisting of a $5 \mathrm{~mm}$ lithium drifted silicon detector followed by seven $\mathrm{cm}$ of germanium (see Fig. 10). This was placed in a thin spherical scattering chamber designed by Hans Gutbrod, on the outside of which were 80 scintillation counters covering the whole forward hemisphere (see Figs. 11 \& 12), because we had learned that in order to select high multiplicity events you have to detect almost all the charged particles. An exhaustive set of data was published for protons ${ }^{8}$ and pions 9,10 with beams as heavy as $40_{A r}$, but it was soon discovered that the many different theoretical models then availate all agreed with the proton data within a factor of two. Clearly, single particle inclusive measurements with associated multiplicity were not sufficient to distinguish between the models.

\section{THE PLASTIC BALL}

Thoughts then turned to measuring all the parlicles in each event. However, in 1979 the GSI-LBL collaboration split up, with Reinhard Stock and Andres Sandoval starting a group to work at the Bevalac Streamer Chamber. Just before, Reinhard had discouraged us from building a $4 \pi$ liquid argon detector because of the difficulties involved. Then, one morning, Hans arrived at work and said he knew how to build a $4 \pi$ detector. The key concept was putting two scintillators on one phototube. Later on we learned that Denys Wilkinson had published this idea 27 years earlier and called it phoswich. Hans-Georg Ritter was brought in to help build this detector. 
Thus, Hans, Hans-Georg, and myself formed the leadership of this other GSI-LBL collaboration, now called the Plastic Ball group.

While the Ball was being designed the outer part of the Plastic Wall was built at LBL. It was first used in 1979 as a forward angle array in conjunction with the existing thick silicon-germanium telescope in its spherical scattering chamber. The Ball took one year to design and to obtain the scintillators from Japan, and one year for the actual construction ${ }^{11}$. In 1981 it was ready to take beam with an augmented Plastic Wall (see Figs. 13 \& 14). In 1982 the new Bevatron vacuum tank was installed and the beams delivered began to increase in mass. Thus the Plastic Ball proved to be the right detector in the right place at the right time.

Of the Plastic Ball group in 1983 (sce Fig. 15) ${ }^{12}$, Hans Gutbrod, Hans-Georg Ritter, Karl-Heinz Kampert, Hans-Ake Gustafsson, Burkhard Kolb, and myself are still working together in WA80 at CERN. Howard Wieman is at Berkeley developing a new $4 \pi$ detector, a TPC, in conjunction with Hans-Georg Ritter. Tim Renner, Bemhard Ludewigt, and Tony Warwick are still at Berkeley working in other divisions of the Laboratory. Mohan Doss is at the University of Saskatchewan.

\section{COLLECTIVE FLOW}

We now faced the new challenge of how to analyze the $4 \pi$ data. We tried looking at a few events in the center of mass but that was not very instructive. Hans-Georg Ritter, using a global analysis method called sphericity, was able to show in 1984 from our data with projectiles as heavy as niobium that, in fact, there were finite flow angles away from $0^{\circ}$ (see Figs. 16 \& 17 ). If you looked at the medium high multiplicity events in the niobium plus niobium collisions, you could see the matter flowing off to one side. This was the discovery of the collective flow of nuclear matter. ${ }^{13}$ The effect was not readily visible in the calcium plus calcium data. A year later when we had gold pius gold data, the effect was very evident.

This collective flow effect was studied systematically as a function of multiplicity, target-projectile mass, and beam energy. 14,15 Our premise in doing this was that if one is ever going to learn about the equation of state of nuclear malter at high density, it is going to be through collective properties of high energy nuclear collisions such as this collective flow.

In 1984 we had the tenth anniversary of a very productive CSI-LBL collaboration. To commemorate this, we issued a souvenir photo which contained one picture of a Plastic Ball event and one picture of a streamer chamber event, mepresenting the two GSI-LBL collaborations.

Improvements were made to the Plastic Ball in 1985 so that the Mall, which was approximately the forward hemisphere in the center of mass for $200 \mathrm{MeV} /$ nucleon equal mass coliisions, could detect intermediate mass tragments all the way from protons up through fluorine nuclei. Barbara Jacak and John Harris joined us and we saw that the heavy fragments have more collective flow than the lighler ones ${ }^{16}$. There is still more information in this data which has not been analyzed yet, which I think will lead to a better understanding of multifragmentation.

\section{SUMMARY OF THE PLASTIC BALL}

Collective flow was not the only result from the Plastic Ball. A summary of all the Plastic Ball physics would include the following: the average momentum in the reaction plane, which is an indication of the pressure built up in the reaction; rapidity distributions, $d N / d y$, which are an 
indication of thermalization or stopping; ratios of clusters, like deuterons to protons, from which we obtained information about entropy: even two-particle correlations, which led to information about the size of the source; and finally the intermediate mass fragments, which are expected to lead to information about multifragmentation. We have actually just finished writing a review paper called "Plastic Ball Experiments." 17 The Plastic Ball filter, describing the acceptance of the Plastic Ball, is available as a Fortran program on EARN/Bitnet from POSKQLBL. We believe that a systematic comparison of filtered theoretical simulations with the Plastic Ball data as a function of multiplicity, target-projectile mass, and beam energy, including not only collective flow, but also other observables such as $\mathrm{dN} / \mathrm{dy}$ and cluster production, will eventually lead to a quantitative understanding of the nuclear equation of state.

As a slight digression, I want to talk about the terminology used at this conference. The experimentalists have talked about participant side splash and collective flow while the theoreticians, for the same phenometion, have been using words like shock waves, bounce off, and squecze out. Experimentalists should be allowed to name the effects that they discover. Shock waves, a theoretical concept, is probably very important in understanding collective flow, but colleclive flow describes experimentally what is observed. For the more quantitative description, the slope at mid-rapidity on a $p_{x}$ vs. $y$ plot, we have used the words flow or flow parameter. In retrospect, I think we should have used the words directed flow. The recent observation that there is more fiow perpendicular to the reaction plane than in the reaction plane we have called squeeze out, in agreement with the theoretical prediction, which was called off-plane squeeze-out. The word bounce off, which we use for the spectator recoil, so far has had no word assigned to it by the theoreticians.

\section{CERN}

In 1986 the Plastic Ball was put in a big box and shipped off to CERN to start a new life as a target rapidity detector for heavy ion reactions at energies up to $200 \mathrm{GeV} /$ nucleon (sce Fig. 18) in experiment WA80 at the SPS at CERN. 18 Again, this is a factor of 100 increase in beam energy, opening up a whole new exciting field where we have to learn how to do the experiments and analyze the data, with theoretical developments going on in parallel.

The other GSI-LBL collaboration, the steamer chamber group, also went to CERN to do an experiment called NA35. This year there is hope that these two GSI-LBL collaborations will rejoin for the expected program with lead beams at the CERN SPS. This will bring back together these very fruitful and friendly collaborations, continuing the long history of GSI-LBL cooperation.

\section{ACKNOWLEDGEMENTS}

1 would like to thank all my colleagues who made this exciting history possible, and the theoreticians who gave this work meaning. Also, I would like to thank Walter Greiner for inviting me to present this history talk, and then encouraging me to write it up. 


\section{REFERENCES}

1. A.M. Poskanzer, G.W. Butler, and E.K. Hyde, Phys. Rev. C3, 882 (1971).

2. A.M. Zebelman, A.M. Poskanzer, J.D. Bowman, R.G. Sextro, and V.E. Viola, Phys. Rev. C11, 1280 (1975).

3. H.G. Baumgardt, J.U. Schott, Y. Sakamoto, E. Schopper, H. Stöcker, J. Hoffmann, W. Scheid, and W. Greiner, Z. Physik A273, 359 (1975).

4. A.M. Poskanzer, R.G. Sextro, A.M. Zebelman, H.H. Gutbrod, A. Sandoval, and R. Stock, Phys. Rev. Lett. 35, 1701 (1975).

5. H.H. Gutbrod, A. Sandoval, P.J. Johansen, A.M. Poskanzer, J. Gosset, W.G. Mcyer, G.D. Westfall, and R. Stock, Phys. Rev, Lett. 37, 667 (1976).

6. G.D. Westfall, J. Gosset, P.J. Johansen, A.M. Poskanzer, W.G. Meyer, H.H. Gutbrod, A. Sandoval, and R. Stock, Phys. Rev. Lelt. 37, 1202 (1976).

7. J. Gosset, H.H. Gutbrod, W.G. Meyer, A.M. Poskanzer, A. Sandoval, R. Stock, and G.D. Westrall, Phys. Rev, C16, 629 (1977).

8. A. Sandoval, H.H. Gutbred, W.G. Meyer, R. Stock, Ch. Lukner, A.M. Poskanzer, J. Gosset, J.-C. Jourdain, C.H. King, G. King, Nguyen Van Sen, G.D. Westfall, and K.L. Wolf, Phys. Rev. C21, 1321 (1980).

9. K.L. Wolf, H.H. Gutbrod, W.G. Meyer, A.M. Poskanzer, A. Sandoval, R. Stock, J. Gosset, C.H. King, G. King, Nguyen Van Sen, and G.D. Westfall, Phys. Rev. Lett. 42, 1448 (1979).

10. K.L. Wolf, H.H. Gutbrod, W.G. Mcyer, A.M. P'oskanzer, A. Sandoval, R. Stock, J. Gosset, J.-C. Jourdain, C.H. King, G. King, Nguyen Van Sen, and G.D. Westfall, Phys. Rev, C26, 2572 (1982).

11. A. Baden, H.H. Gutbrod, H. Löhner, M.R. Maier, A.M. Poskanzer, T. Renner, H. Riedesel, H.G. Ritter, H. Spicler, A. Warwick, F. Weik, and H. Wieman, Nucl. Instr. and Meth. 203, 189 (1982).

12. Other members of the Plastic Ball group have included Rudolf Albrecht, Andrew Baden, Peter Beckmann, Göran Clacsson, John Harris, Barbara Jacak, Per Kristiansson, Francois Lefebvres, Herbert Löhner, Michacl Maier, Hubertus Riedesel, Rainer Schicker, Hans Rudolf Schmidt, Tcodor Siemiarczuk, Helmuth Spieler, Joana Stepaniak, Larry Teitelbaum, Mark Tincknell, Friedeman Weik, Steve Weiss, and Wojciech Wislicki.

13. H.-A. Gustafsson, H.H. Gutbrod, B. Kolb, H. Löhner, B. Ludewigt, A.M. Poskanzer, T. Renner, H. Riedesel, H.G. Ritter, A. Warwick, F. Weik, and H. Wieman, Phys. Rev. Lett. 52, 1590 (1984).

14. K.G.R. Doss, H.-A. Gustafsson, H.H. Gutbrod, K.H. Kampert, B. Kolb, H. Löhner, B. Ludewigt, A.M. Poskanzer, H.G. Ritler, H.R. Schmidt, and H. Wieman, Phys. Rev. Lett. 57, 302 (1986).

15. H.-A. Gustafsson, H.H. Gutbrod, J.W. Harris, B.V. Jacak, K.-H. K.ampert, B. Kolb, A.M. Poskanzer, H.G. Ritter, and H.R. Schmidt, Modern Physics Lctt. 3, 1323 (1988).

16. K.G.R. Doss, H.- $\AA$. Gustafsson, H. Gutbrod, J.W. Harris, B.V. Jacak, K.-H. Kamperl, B. Kolb, A.M. Poskan?er, H.G. Ritter, H.R. Schmidt, L. Teitelbaum, M. Tincknell, S. Weiss, and H. Wieman, Phys. Rev. Lett. 59, 2720 (1987).

17. H.H. Gutbrod, A.M. Poskanzer, and H.G. Ritter, to be published in Reports in Progress in Physics (1989).

18. Albrecht et al., CERN Report CERN/SPSC/85-39 (1985). 


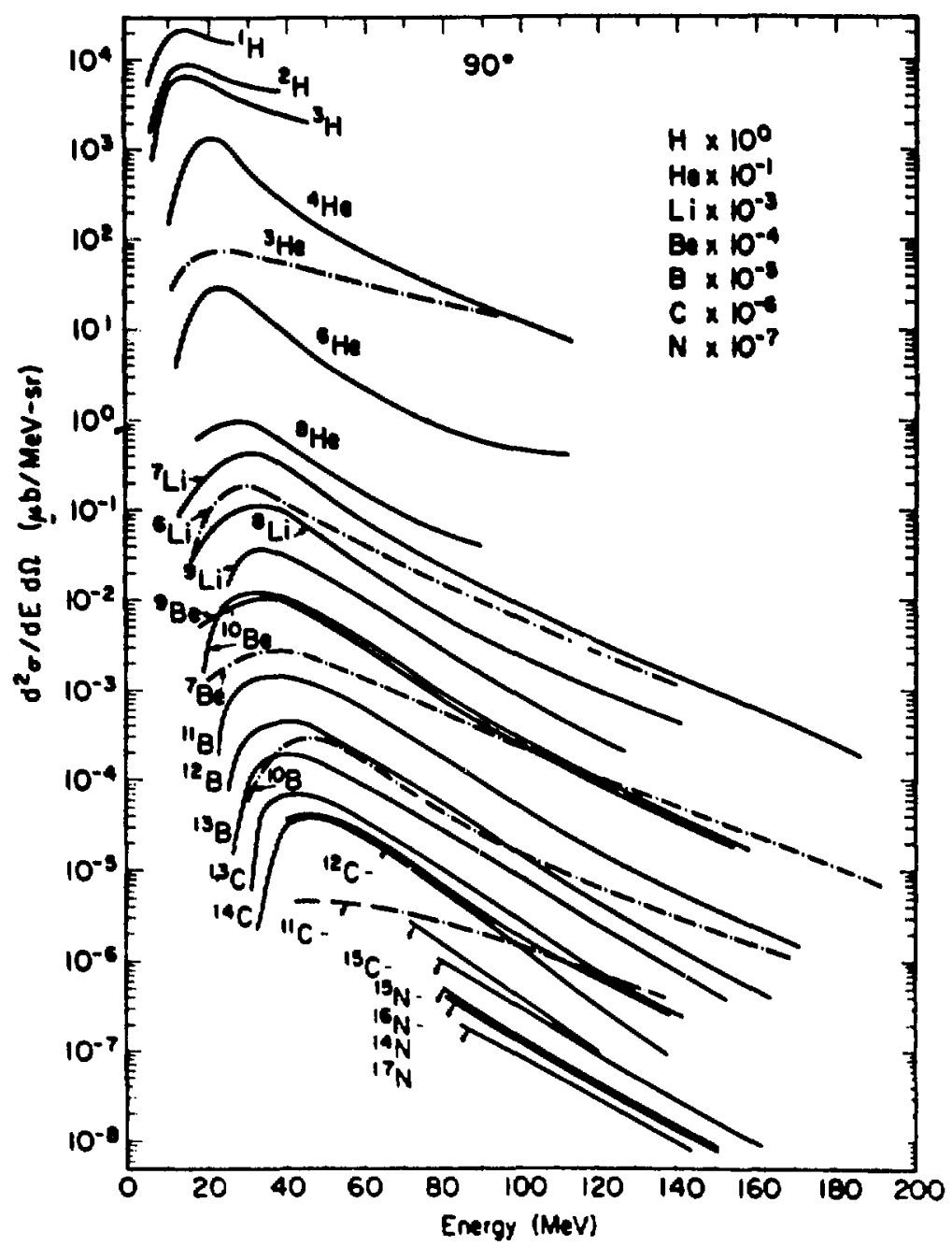

Fig. 1. Laboratory energy spectra at $90^{\circ}$ to the beam for $5.5 \mathrm{GeV}$ protons on an uranium target. The most neutron deficient isotopes are shown as dot-dash lines. 

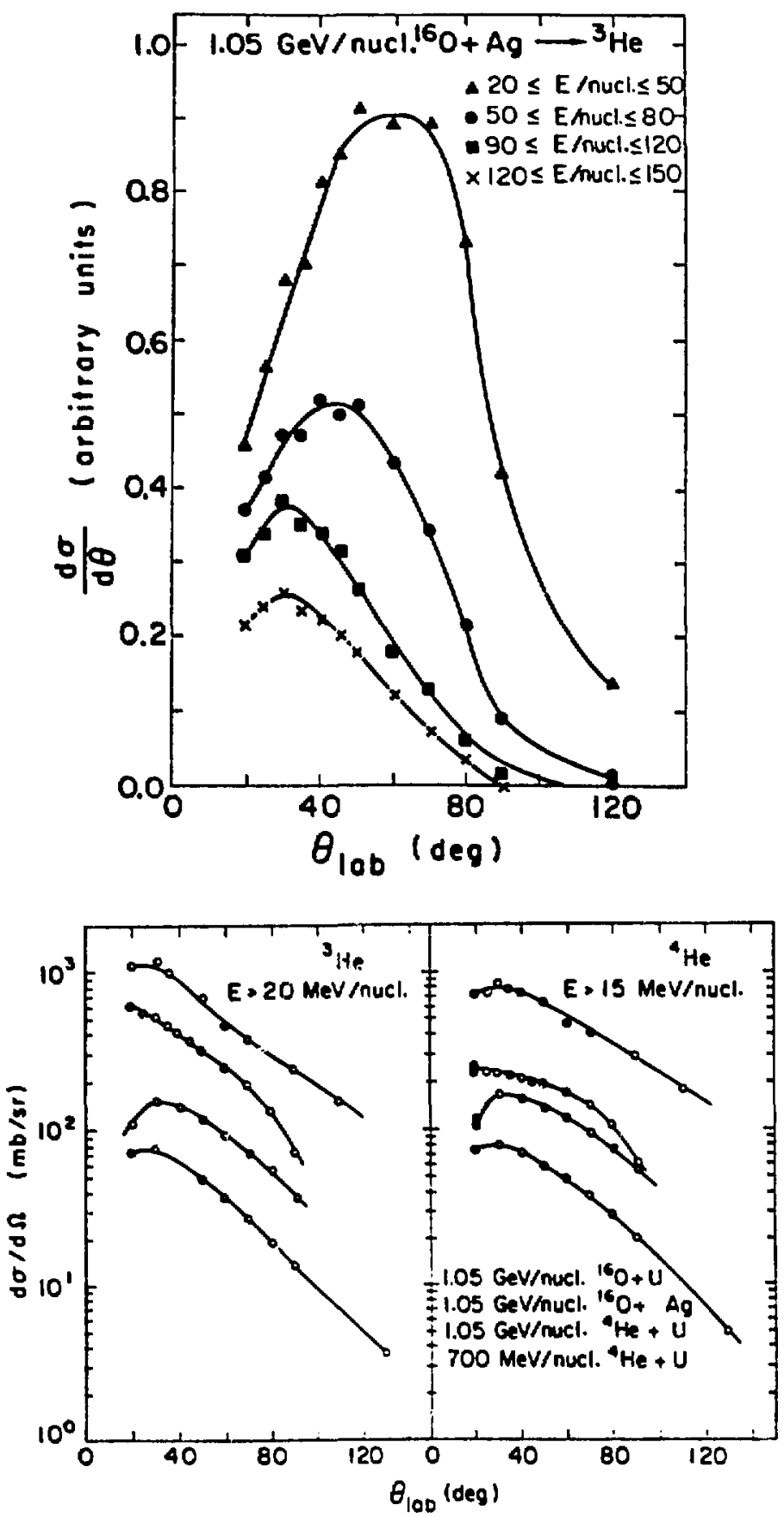

Fig. 3. Laboratory angular distributions plotted as do/d $\theta$ in the top figure, and as do/onin the bottom figure. The top curve in the top figure is reploted as the second from the top curve in the lower left figure. 

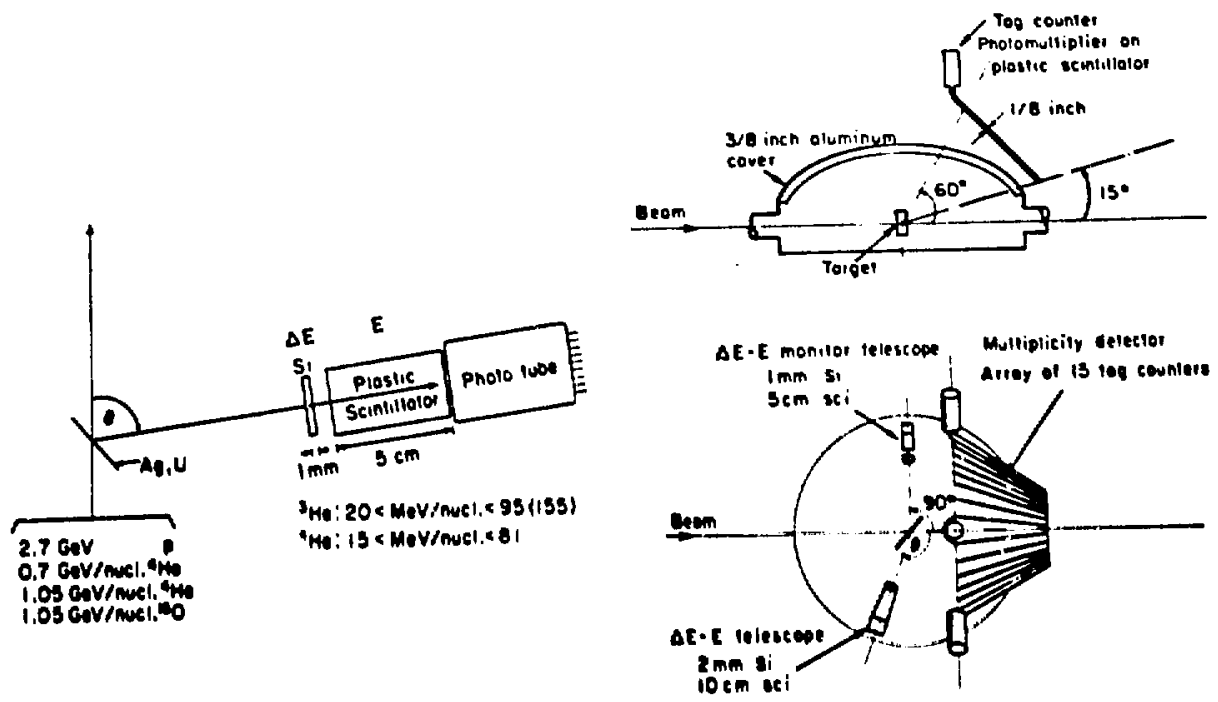

Fig. 2. The first silicon-plastic telescope.

Fig. 1. The scattering chamber containing the second silicon-plastic telescope with the 15 counter tag array.

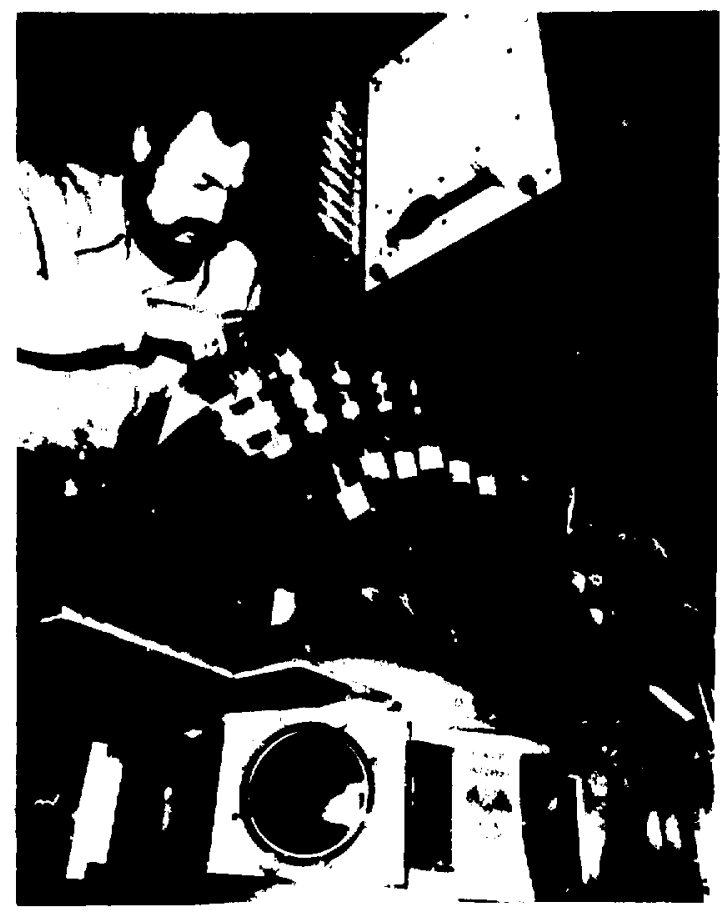

Fig. 5. Hans Gutbrod with the 15 counter tag array and scattering chamber. 


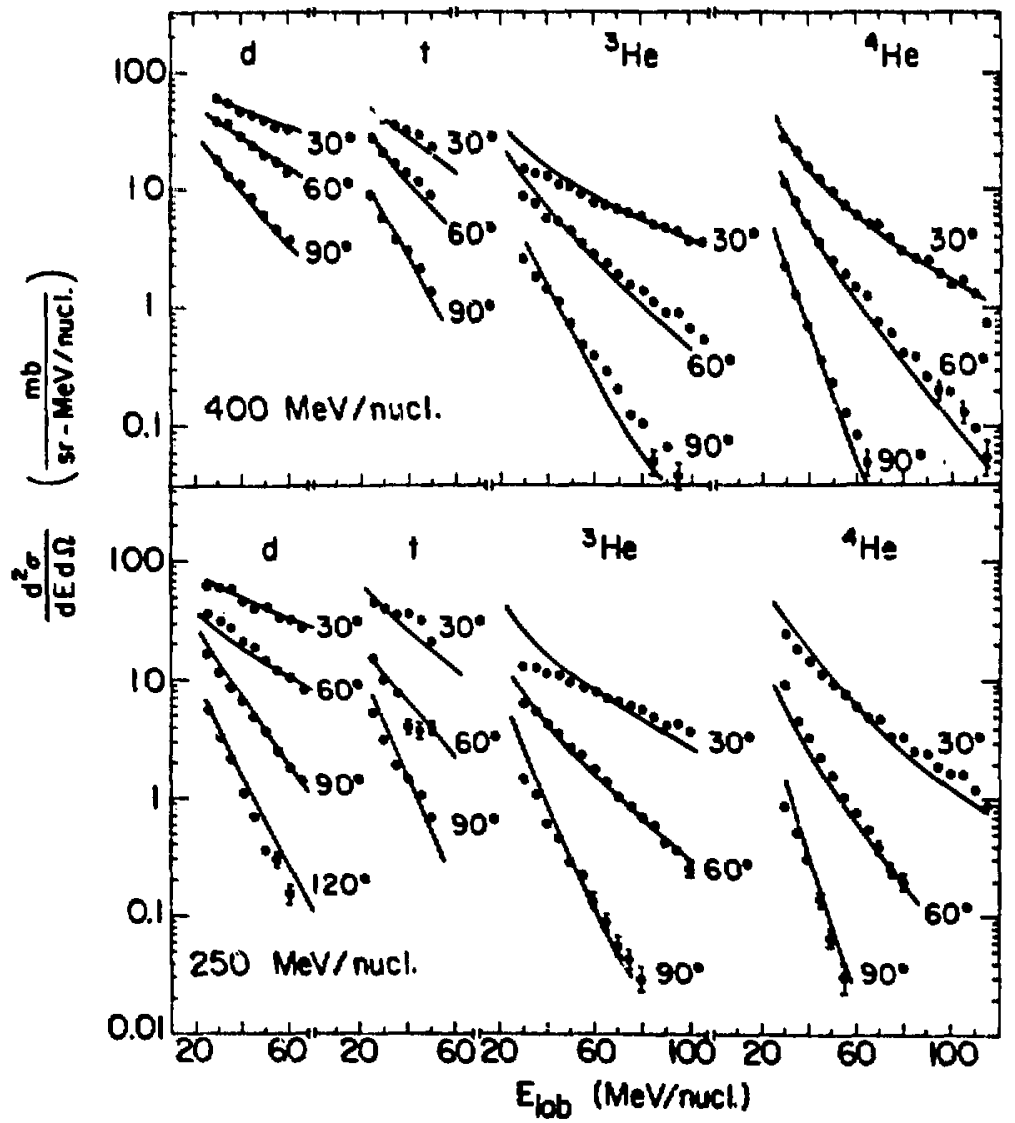

Fig. 6. Double differential cross sections for $d, t,{ }^{3} \mathrm{He}$, and $\mathbf{4}_{\mathrm{He}}$ from $20 \mathrm{Ne}+\mathrm{U}$ at two bombarding energies. The solid curves from the coalescence Model are calculated from the proton data raised to the $A^{\text {th }}$ power. 


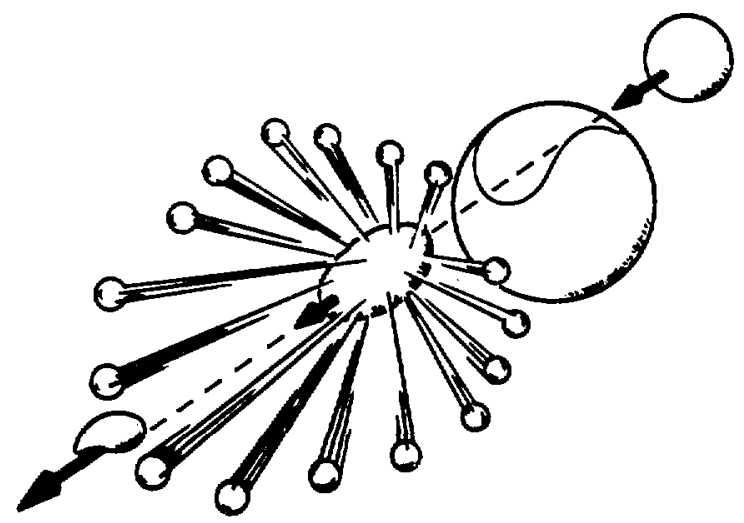

Fig. 8. An artiat' view of the Firebald Model howing the spectatorpartielpant genmetry.

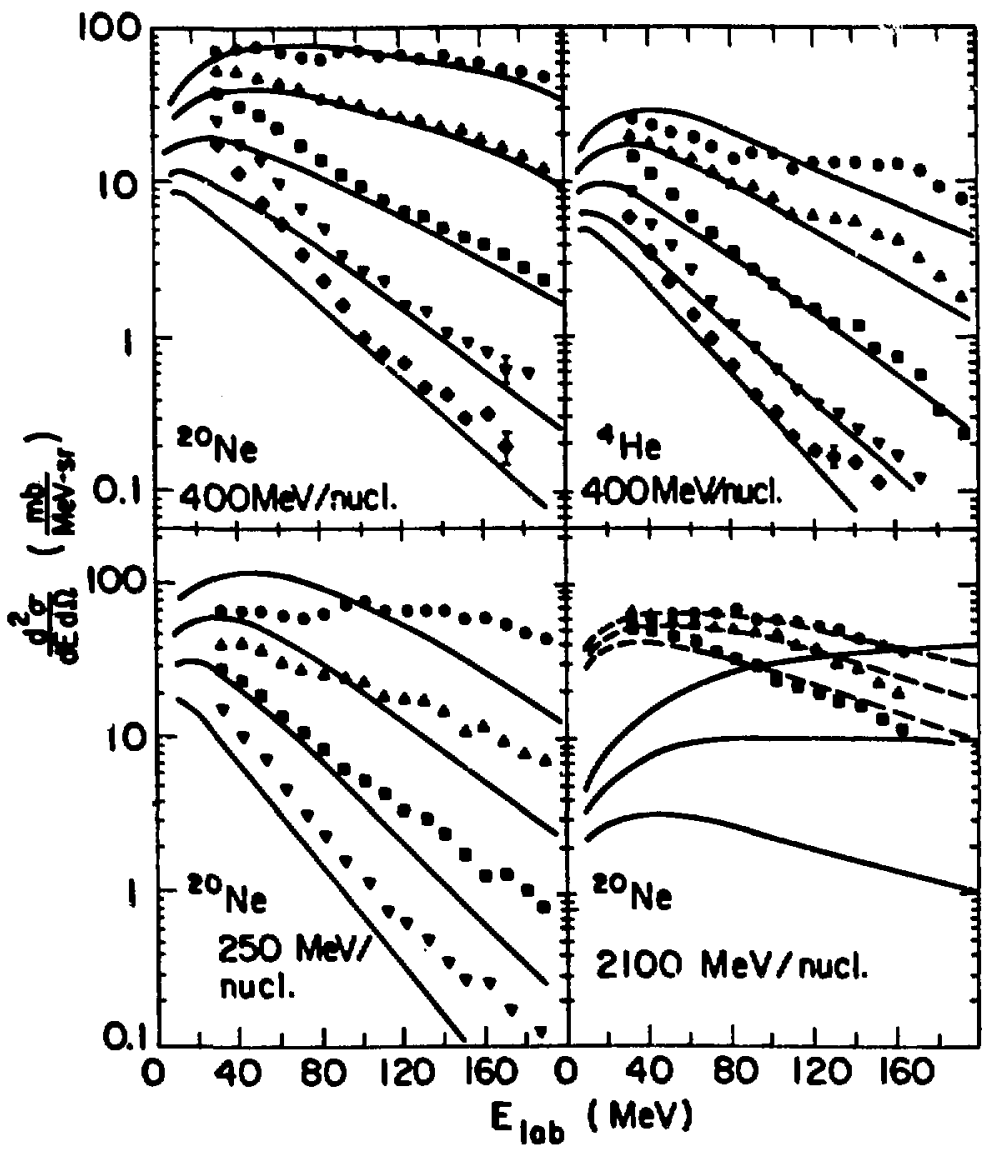

Fig. 7. Double differential cross sections for protons from 4 He and $20_{\text {Ne }}$ on uraniun targets. The curves from top down as far as they go are for the laboratory angles of $30^{\circ}, 60^{\circ}, 90^{\circ}, 120^{\circ}$, and $150^{\circ}$. The solid curves are calculated by the Fireball Model. The dashed curves on the lower right are fits from a two source Fireball Model. 

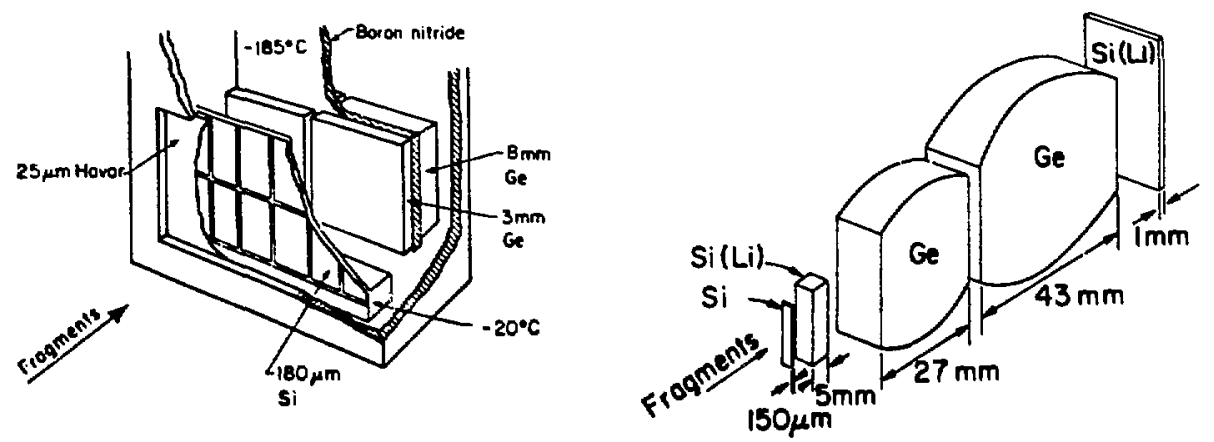

Fig. 9. The large area $\left(20 \mathrm{~cm}^{2}\right)$ ellicon-germanium telescope.

Fig. 10. The thlck silicon-germanium telescope.

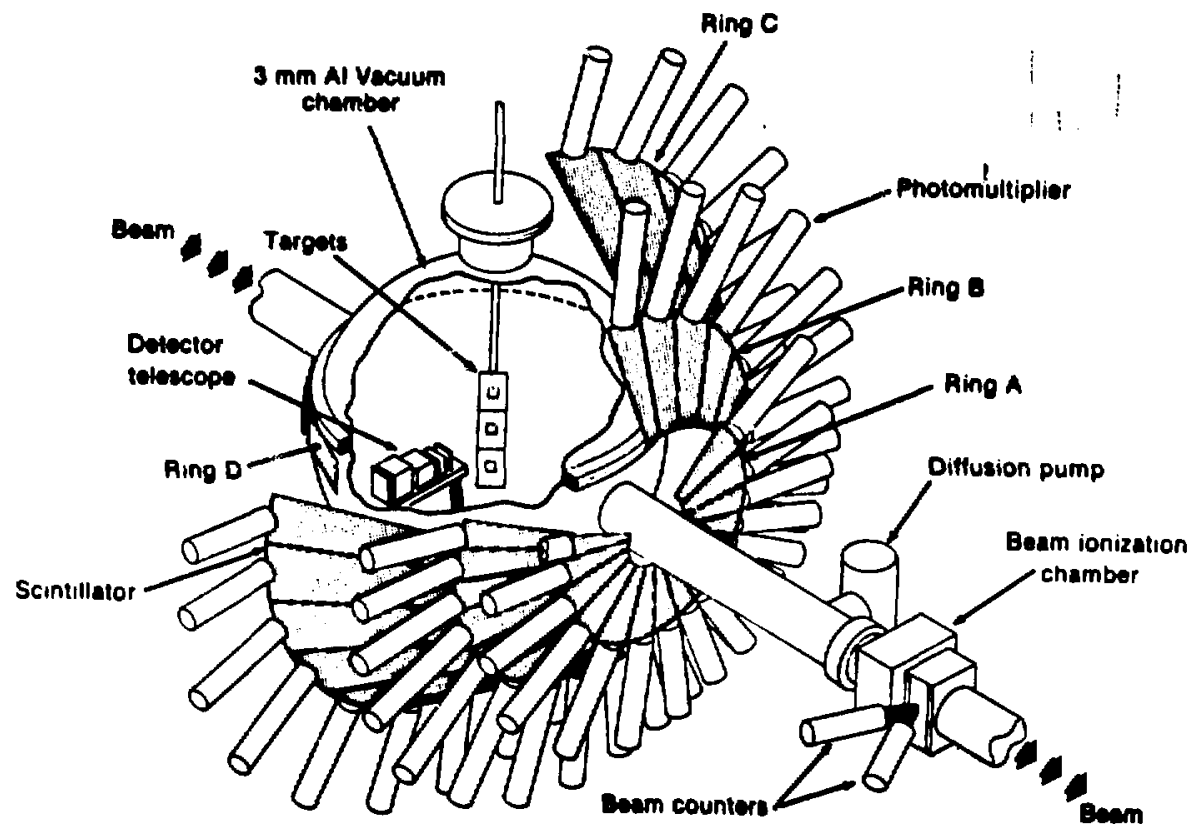

Fig. 11. The spherical scattering chamber containing the thick silicongermanium telescope with the 80 counter associated multiplicity array. 


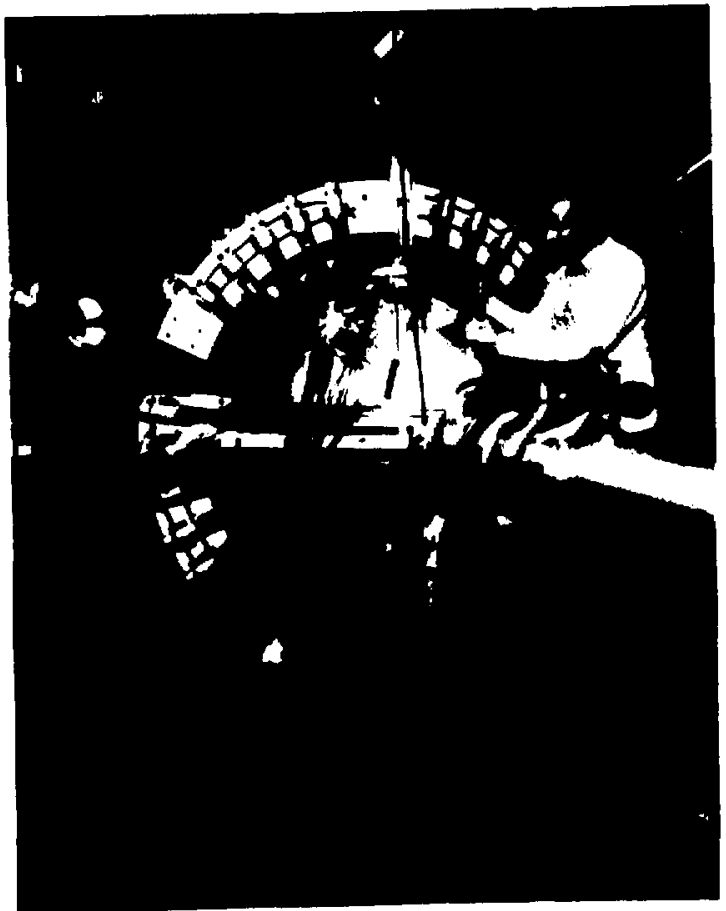

Fig. 12. Art Poskarizer (left) and Reirhard Stock (right) next to the spherical scattering chamber. 


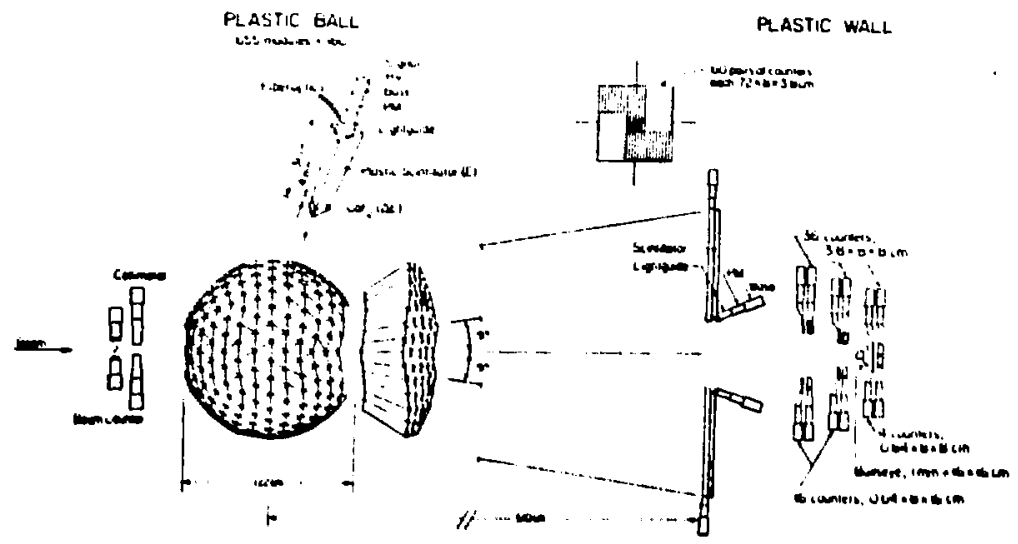

Eig. 13. The Plastic Ball/Wall layout. The modules from $9^{\circ}$ to $30^{\circ}$ are called the Mall. On the top are view of a single module (left) and a view of the wall as seen by the beam (right).

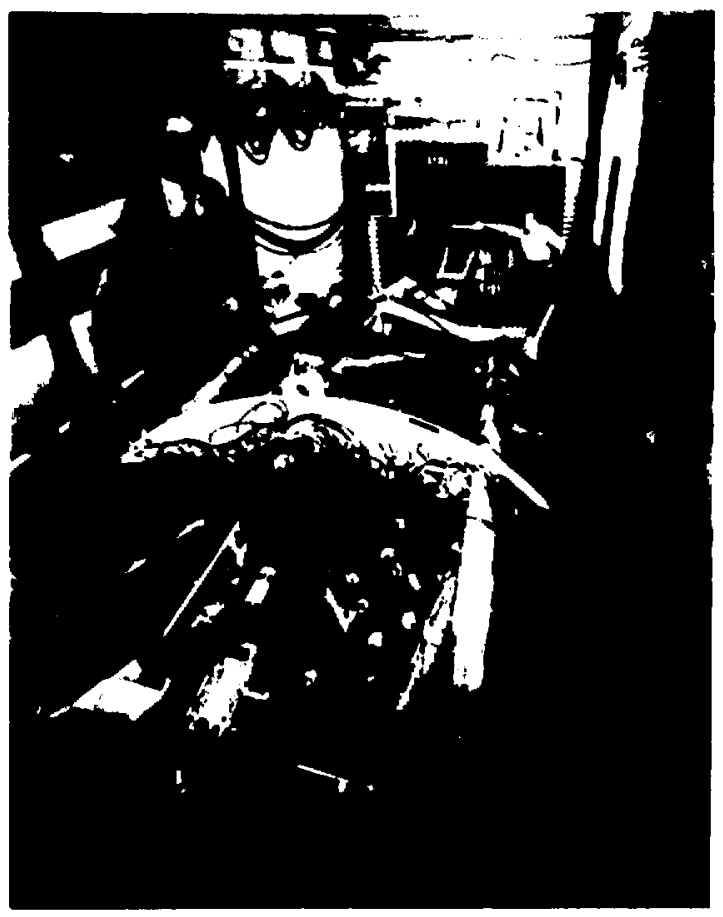

Fig. 14. The Plastic Bal1/Wall. Hans-Georg Ritter and Hans Gutbrod are above the Ball, and Art Poskanzer is in front of the wall. 


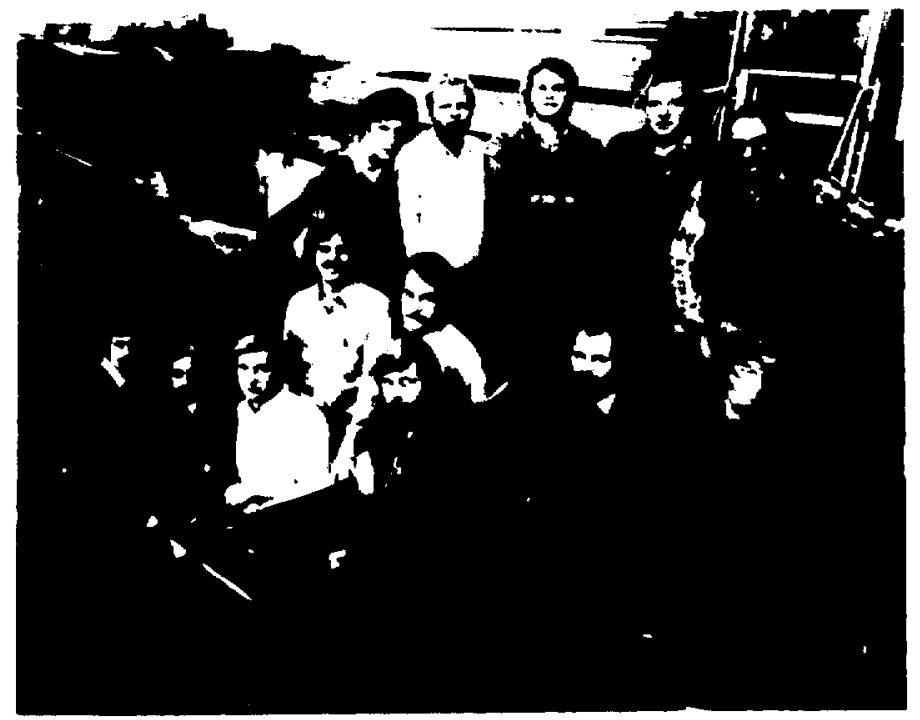

Fig. 15. The Plastic Bald group in 1983. From left to right front row: Hans-Georg Ritter, Mohan Doss, Howard Wieman, and Burkhard Kolb. Middle row: Tim Renner, Tony Warwick, and Karl-Heinz Kampert. Back row: Herbert Löhner, Hans-Ake Gustafsson, Bernhard Ludewigt, Hans Gutbrod, and Art Poskanzer.

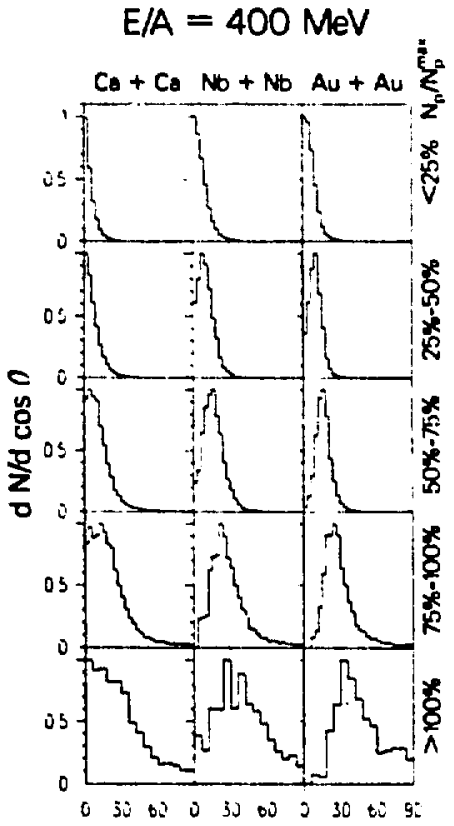

Flow angle 0 (degrees)

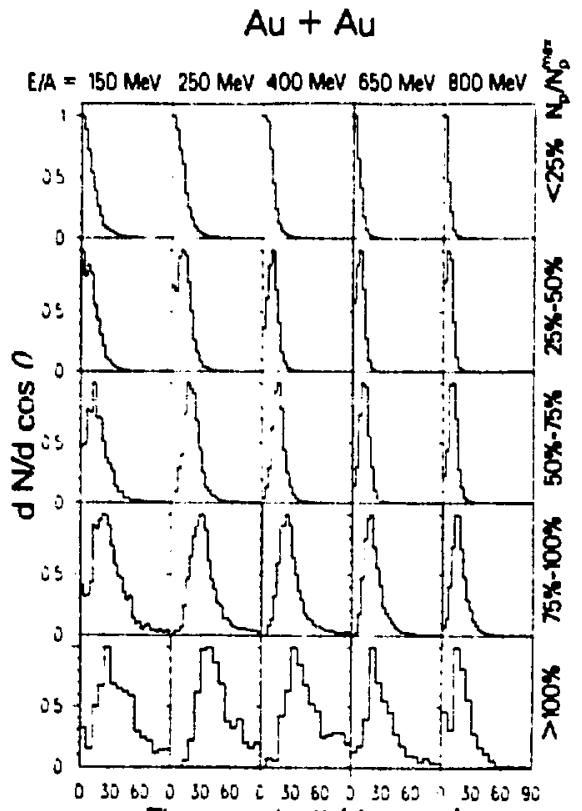

Flow angle $U$ (degrees)

Fig. 16. Flow angle distributions for three equal mass target-projectile combinations and five normalized multiplicity bins at $400 \mathrm{MeV} / \mathrm{nucleon}$. Fig. 17. Flow angle distributions for five beam energies and five normalized multiplicity bins for Au + Au. 


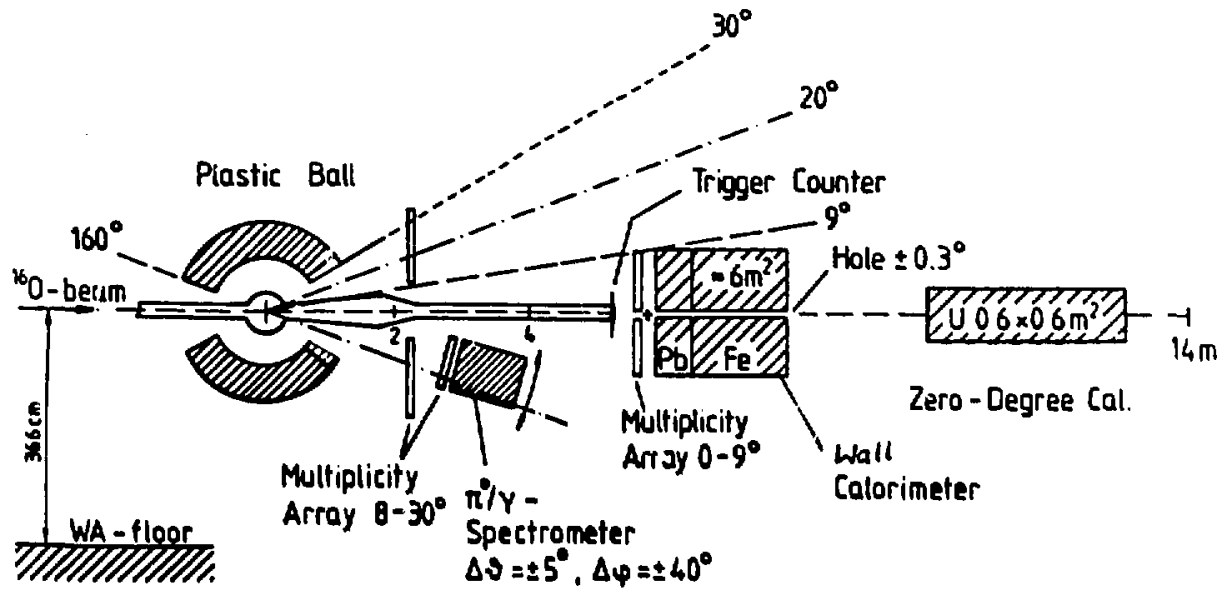

Fig. 18. Layout of the wA80 experiment showing the Plestic Ball. 